
ABSTRACT TECHNOLOGIC PAPER NO. 9, THE BUREAU OF
STANDARDS.

BY

H. W. Bearce,

Assistant Physicist.

Sixteen samples of linseed oil of known origin and purity were tested. A complete history of these samples is given in Technologic Paper No. 9, Bureau of Standards, and also in the I9I I Proceedings of the American Society for Testing Materials. Six samples of gum turpentine, three samples of wood turpentine, two samples of "wood spirits," and one sample of "oil" of turpentine were also tested.

The density of each sample was determined at $10^{\circ}, 20^{\circ}, 30^{\circ}$, and $40^{\circ} \mathrm{C}$. by the method of hydrostatic weighing. Special apparatus was employed by means of which any turpentine between $10^{\circ}$ and $40^{\circ} \mathrm{C}$. could be obtained and automatically maintained sensibly constant for any desired length of time. The densities were determined by weighing in the sample at each temperature a plummet or sinker of known mass and volume, the sinker having been calibrated by weighing in twice-distilled water.

The temperatures were read on two mercurial thermometers suspended in a glass tube placed parallel and adjacent to the tube containing the sample.

The sinker used in the density determinations was of Jena I $^{\text {III }}$ glass, ballasted with mercury, and had approximately the following dimensions: length, $30 \mathrm{~cm}$; diameter, $\mathrm{I}_{5} \mathrm{~cm}$; volume, 50 c.c.; mass, Ioo g.

In making a density determination the method of procedure was as follows: The water in the outside bath was brought to the desired temperature by proper adjustment of the heating and cooling coils. After sufficient time had elapsed to allow the apparatus to attain temperature equilibrium, observations were begun. First, a weighing was made with the sinker suspended in the liquid, then the two thermometers were read; next, a tare weighing was made with the suspension wire still passing through the surface of the liquid, but with the sinker detached and resting on the bottom of the containing tube; then a second weighing with the sinker attached, and after that a second reading of the thermometers. 
After completing the observations on a sample at the four temperatures $10^{\circ}, 20^{\circ}, 30^{\circ}$, and $40^{\circ} \mathrm{C}$., the density at each temperature was calculated by means of the equation

$$
D_{t}=\frac{W-\frac{\left(w-w_{2}\right)+\left(w-w_{2}\right)}{2}\left(1-\frac{\rho}{8.4}\right)}{V_{\imath}}
$$

In which $D_{t}=$ density of sample at temp. t. (in $\mathrm{gms} / \mathrm{ml}$ ).

$W=$ weight of sinker in vacuo.

$w=$ weighing with sinker off.

$w_{1}$ and $w_{2}=$ weighing with sinker on.

$\rho=$ air density.

$8.4=$ assumed density of brass weights.

$V_{t}=$ volume of sinker at temp. $t$.

After calculating the density at each temperature, a least squares reduction was applied to the calculated results in order to find the most probable value of the density at each temperature. It was assumed that the equation $D t=D+\propto(t-x)+\beta(t-x)^{2}$ represents sufficiently well the rate of expansion. The very small residuals obtained show that the assumption was justified.

A summary of the results of the investigation is here given.

\section{SUMMARY OF RESULTS}

TABLE I

The Density and Thermal Expansion of Linseed OIl at Temperatures BETWEEN $10^{\circ}$ AND $40^{\circ} \mathrm{C}$

\begin{tabular}{|c|c|c|c|c|c|c|c|}
\hline Sample No. & $D^{10}{ }^{10^{\circ}} C$ & $D^{20^{\circ}}{ }^{\circ} C$ & $D_{4^{\circ}}^{30^{\circ}} C$ & $D^{40^{\circ}}{ }^{\circ} \mathrm{C}$ & $D_{4^{\circ}}^{25^{\circ} \mathrm{C}}$ & $a \times 10^{7}$ & $\beta \times 10^{9}$ \\
\hline & .93513 & .92823 & $.92 \quad 139$ & .91460 & .92480 & -6844 & +262 \\
\hline & .93526 & $.9284 I$ & .92158 & .91475 & .92499 & & \\
\hline & .93561 & .92875 & $.92 \quad 193$ & $.9 \mathrm{I} 5 \mathrm{I} 4$ & $.92 \quad 534$ & & +192 \\
\hline & $.93 \quad 598$ & $.929 \mathrm{II}$ & $.92 \quad 226$ & .91543 & $.92 \quad 568$ & & +90 \\
\hline I I & .93606 & .92920 & $.92 \quad 235$ & $.9155^{2}$ & $.92 \quad 578$ & & +5 \\
\hline & .93614 & .92928 & $.92 \quad 244$ & $.9156 \mathrm{I}$ & $.92 \quad 5^{86}$ & & +90 \\
\hline & .93624 & .92938 & .92255 & .9I 573 & .92596 & & + \\
\hline & .93668 & $.9298 \mathrm{I}$ & $.92 \quad 295$ & $.916 \mathrm{II}$ & .92638 & & $+x I$ \\
\hline & $.93 \quad 704$ & .93016 & $.92 \quad 329$ & .91642 & .92672 & & +3 \\
\hline & 0 937 . & .93022 & $.92 \quad 33^{8}$ & .91657 & .92680 & & +16 \\
\hline & .93716 & $.9303 \mathrm{I}$ & $.92 \quad 347$ & .91664 & .92688 & & +78 \\
\hline & $.9373^{8}$ & .93049 & $.92 \quad 365$ & .9I 686 & .92706 & & +240 \\
\hline & .93746 & $.93 \quad 062$ & .92377 & .91691 & 92720 & & -88 \\
\hline & .93755 & .93063 & $.92 \quad 378$ & .91 699 & .92720 & & +320 \\
\hline & .93761 & .93073 & $.92 \quad 389$ & .9 I 707 & $.92 \quad 730$ & & +15 \\
\hline & .93789 & .93100 & $.924 \mathrm{I} 3$ & .91727 & $.9275^{6}$ & & +78 \\
\hline ved & & & & & $92 \quad 634$ & -6847 & +120 \\
\hline
\end{tabular}




$$
D_{t}=D_{25}+\propto(t-25)+\beta(t-25)^{2}
$$

Taking for $\propto$ and $\beta$ the mean values of the 16 samples the general equation becomes $D_{t}=D_{25}-0.0006847(t-25)+0.000$ $000 \mathrm{I}_{2}(t-25)^{2}$. If it is desired to reduce the expansion to a single term for use over a short temperature range, this may be done by differentiating the general equation and combining $\propto$ and $\beta$ into a single term, $\propto^{\prime}$, which will be different for different temperatures.

$$
\begin{gathered}
D_{t}=D_{25}+\propto(t-25)+\beta(t-25)^{2} \\
\frac{d D_{t}}{d t}=\propto+2 \beta(t-25)=\propto^{1}
\end{gathered}
$$

Substituting for $t$ the values Io, I5, 20, 25,30, 35, and 40 , gives for the rate of change of density at the different temperatures the following values:

Temper-
ature.
0 C.
I0
15
20
25
30
35
40

$\begin{gathered}\text { Change per } \\ \text { degree } C .\end{gathered}$
0.0006883
.000687 I
.0006859
.0006847
.0006835
.0006823
.000681 I

The results obtained from the six samples of gum turpentine shown in Group I were used in the calculation of Table IV for determining the density of turpentine at various temperatures.

If the general equation $D_{t}=D_{25}+\propto(t-25)+\beta(t-25)^{2}$ be differentiated and the mean values of $\alpha$ and $\beta$ substituted in the first derivative the change of density per degree at different temperatures is seen to be as shown below.

$$
\begin{array}{cc}
D_{t}=D_{25}+\propto(t-25)+\beta(t-25)^{2} & \\
\frac{d D_{t}}{d t}=\propto+2 \beta(t-25)=\text { change of density per degree }=\propto^{1} \\
t & \propto 1 \\
10 & .0008142 \\
15 & 815 \mathrm{I} \\
20 & 816 \mathrm{I} \\
25 & 8170 \\
30 & 8179 \\
35 & 8189 \\
40 & 8198
\end{array}
$$

In calculating Table IV these values of $\propto^{1}$ were taken as the rate of change of density of turpentine having a density of 0.8640 at $20^{\circ} \mathrm{C}$. (this being the mean of the six samples from 
646 Notes from the Bureau of Standards.

\begin{tabular}{|c|c|c|c|c|c|c|c|}
\hline $\begin{array}{l}0 \\
0 \\
q \\
q \\
z\end{array}$ & 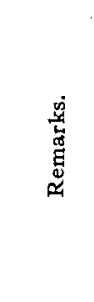 & & 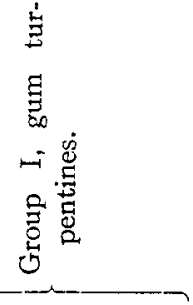 & & 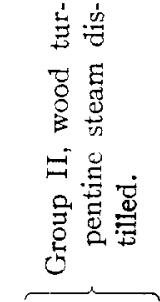 & & 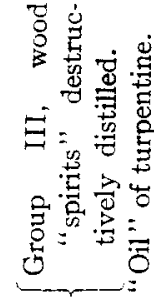 \\
\hline : & 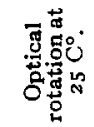 & $\begin{array}{cc}0 & 0 \\
0 & \infty \\
1 & \stackrel{\dot{m}}{+} \\
1 & +\end{array}$ & 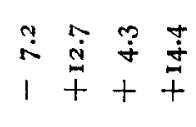 & & $\begin{array}{l}a \hat{i} \\
\hat{i} \\
+\end{array}$ & & 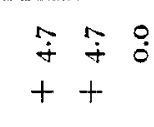 \\
\hline 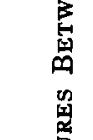 & 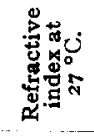 & 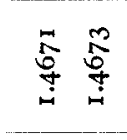 & 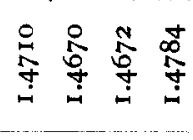 & & 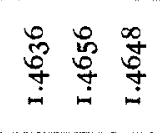 & & 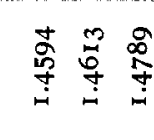 \\
\hline 密. & $\begin{array}{l}\stackrel{a}{\overrightarrow{\hat{े}}} \\
\times \\
\infty\end{array}$ & 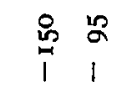 & $\begin{array}{llll}0 & n & \infty & \infty \\
& 1 & 1 & 0\end{array}$ & $\begin{array}{l}\text { से } \\
1\end{array}$ & $\begin{array}{lll}\text { in } & 8 & 8 \\
1 & 1 & 0 \\
1 & 1 & 1\end{array}$ & 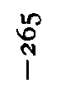 & \begin{tabular}{lll}
0 & $\infty$ & $\infty$ \\
$\stackrel{\infty}{N}$ & $\stackrel{\infty}{N}$ & \multirow{1}{N}{} \\
1 & 1 & 1
\end{tabular} \\
\hline 傿 & $\begin{array}{l}\tilde{\theta} \\
\dot{x} \\
\ddot{\theta}\end{array}$ & $\begin{array}{cc} & 4 \\
0 & 0 \\
\infty & \infty \\
1 & 1\end{array}$ & \begin{tabular}{cccc}
2 & \multirow{2}{*}{} & $\infty$ & 0 \\
0 & 0 & 0 \\
$\infty$ & 0 & 0 & 0 \\
1 & 1 & 1 & 1
\end{tabular} & 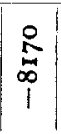 & 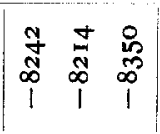 & \begin{tabular}{c}
8 \\
\multirow{2}{0}{} \\
$\infty$ \\
1
\end{tabular} & 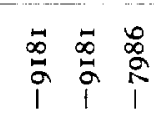 \\
\hline 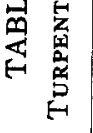 & ing & $\begin{array}{ll}9 & 0 \\
N & 0 \\
10 & 1 \\
0 & 0 \\
0 & 0\end{array}$ & 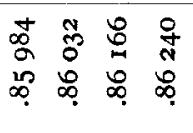 & & 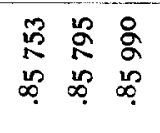 & & 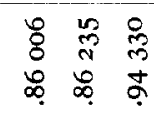 \\
\hline 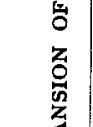 & $\dot{q}_{0}^{\circ}$ & 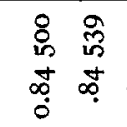 & 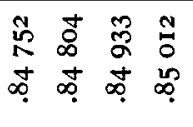 & & 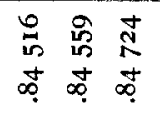 & & 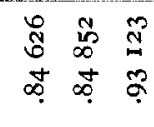 \\
\hline 离 & 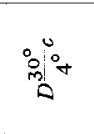 & 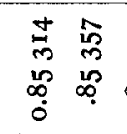 & 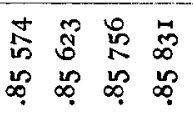 & & 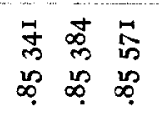 & & 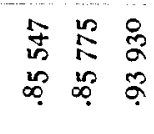 \\
\hline 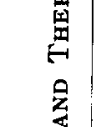 & : & 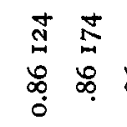 & 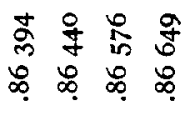 & & 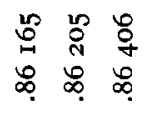 & & 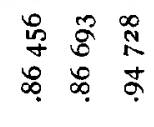 \\
\hline 窎 & 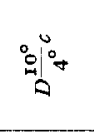 & \begin{tabular}{ll}
\multirow{2}{*}{} & $\infty$ \\
$\sigma$ & $\infty$ \\
0 & 0 \\
$\infty$ & $\infty$ \\
0 & $\infty$
\end{tabular} & 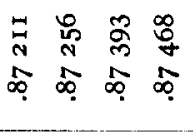 & & 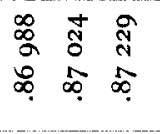 & & 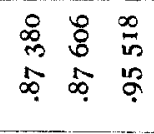 \\
\hline & 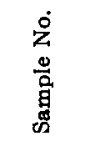 & $\begin{array}{c}\vdots \\
\vdots \\
\vdots\end{array}$ & $\begin{array}{cccc}\vdots & \vdots & \vdots & \vdots \\
& \infty & \vdots & \vdots\end{array}$ & & 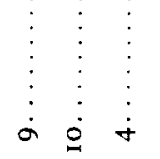 & $\stackrel{\dot{g}}{\stackrel{5}{\Sigma}}$ & $\begin{array}{c}\vdots \\
\vdots \\
\vdots \\
\vdots\end{array}$ \\
\hline
\end{tabular}


which $\propto^{1}$ was derived). For turpentine having a density at $20^{\circ}$ either greater or less than $0.8640 \propto^{1}$ was calculated from mean $D \frac{20^{\circ}}{4^{\circ}}$ and mean $\propto^{1}$ of the three lightest samples and mean $\frac{D_{20^{\circ}}}{4^{\circ}}$ and mean $\propto^{1}$ of the three heaviest samples.

TABLE III

Density of Linseed Oil at any Temperature Between $10^{\circ}$ and $40^{\circ} \mathrm{C}$. From its Density at $20^{\circ} \mathrm{C}$.

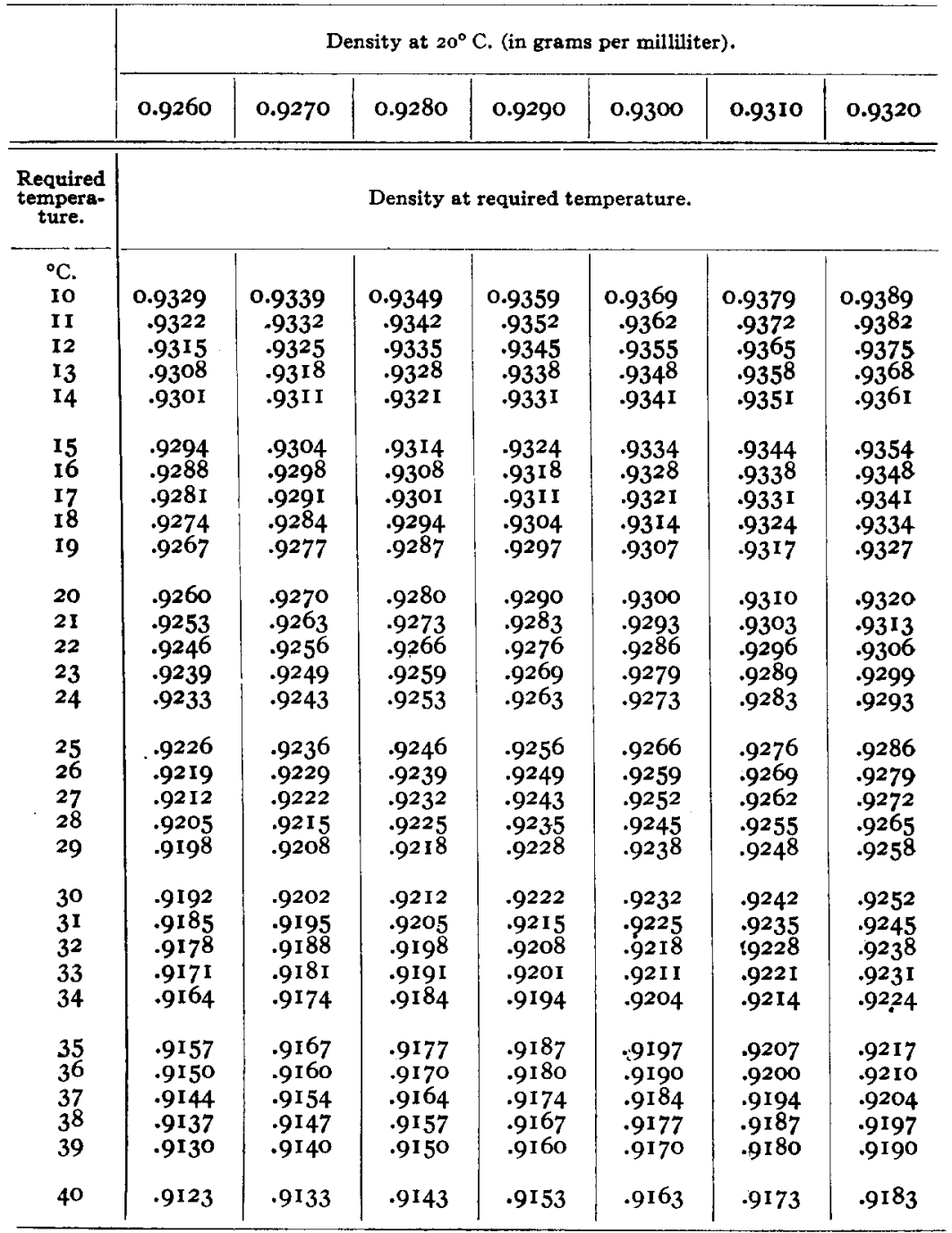




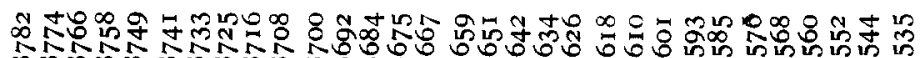

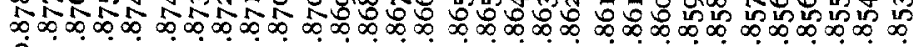
$\dot{0}$

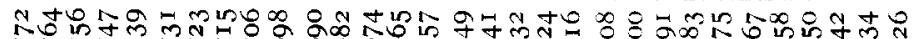

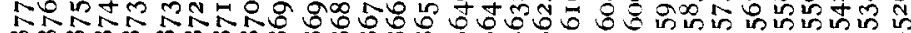

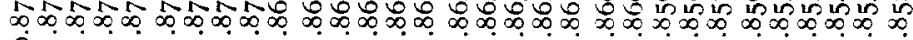
$\circ$

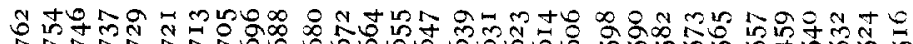

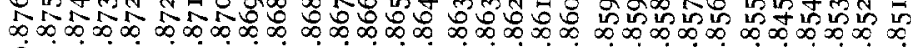
$\dot{0}$

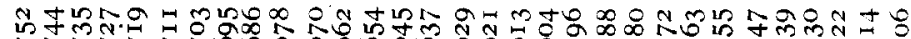

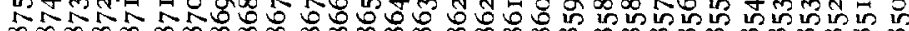

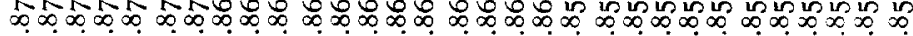
0

年药 STNAR 0

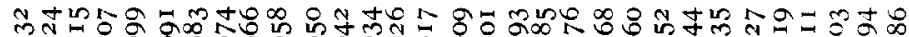

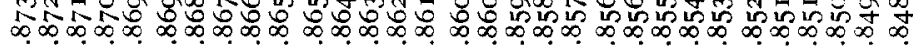
o

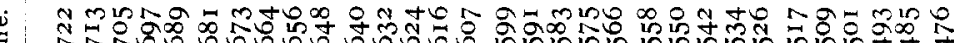

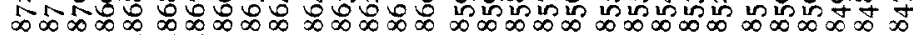
$\dot{0}$

"

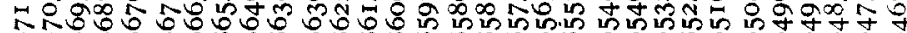

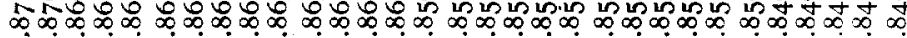
i

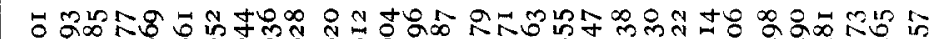

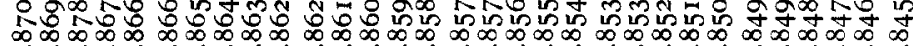
递

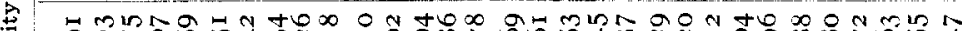
8क्री

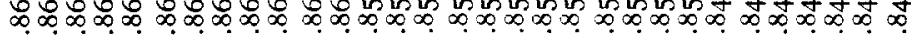
0

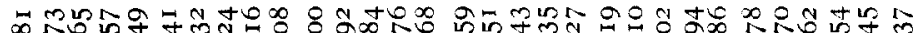

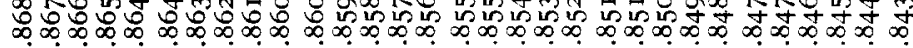
(1)

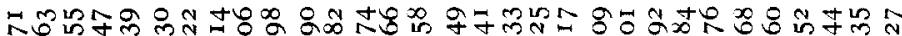

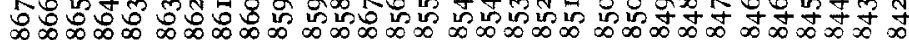
$\dot{0}$

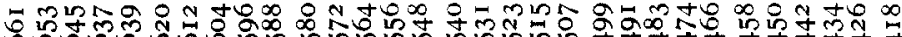

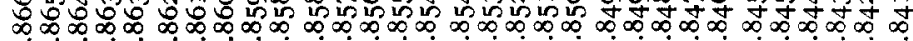

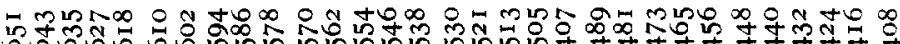

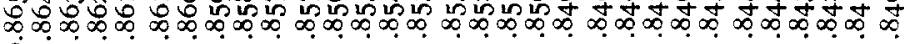
$\circ$

"

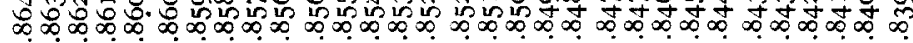
0

m ర0 (5) 